\title{
Mechanisms of nordihydroguaiaretic acid-induced growth inhibition and apoptosis in human cancer cells
}

\author{
T Seufferlein*,', MJ Seckl', E Schwarz ${ }^{3}$, M Beil', G v Wichert', H Baust², H Lührs', RM Schmid' and G Adler' \\ 'Department of Internal Medicine I, University of Ulm, D-8908I Ulm, Germany; ${ }^{2}$ Department of Radiotherapy, University of Ulm, D-8908I Ulm, Germany; \\ ${ }^{3}$ German Cancer Research Center, Applied Tumour Virology, D-69120 Heidelberg, Germany; ${ }^{4}$ Department of Medicine, University of Wuerzburg, \\ D-97080 Wuerzburg, Germany; ${ }^{5}$ Department of Medical Oncology, CRC Laboratories, Hammersmith Hospitals Campus of Imperial College, London \\ WI 2 ONN, UK
}

Lipoxygenase metabolites of arachidonic acid can act as growth promoting factors for various cancer cell lines. Here we demonstrate that the 5-lipoxygenase inhibitor nordihydroguaiaretic acid potently inhibits anchorage-independent growth of human pancreatic and cervical cancer cells in soft agar and delays growth of pancreatic and cervical tumours established in athymic mice. Furthermore, nordihydroguaiaretic acid induces apoptosis of these cancer cells in vitro and in vivo. Potential mechanisms mediating these effects of nordihydroguaiaretic acid were examined. Nordihydroguaiaretic acid had no inhibitory effect on growth and survival signals such as tyrosine phosphorylation of the epidermal growth factor receptor or basal and growth factor-stimulated activities of extracellular signal-regulated kinase 1/2, $\mathrm{p} 70^{56 \mathrm{~K}}$ and AKT but selectively inhibited expression of cyclin DI in the cancer cells. In addition, treatment with nordihydroguaiaretic acid lead to a disruption of the filamentous actin cytoskeleton in human pancreatic and cervical cancer cells which was accompanied by the activation of Jun$\mathrm{NH}_{2}$-terminal kinase and p38 ${ }^{\text {mapk }}$. Similar effects were obtained by treatment of the cancer cells with cytochalasin $\mathrm{D}$. These results suggest that nordihydroguaiaretic acid induces anoikis-like apoptosis as a result of disruption of the actin cytoskeleton in association with the activation of stress activated protein kinases. In conclusion, nordihydroguaiaretic acid could constitute a lead compound in the development of novel therapeutic agents for various types of cancer.

British Journal of Cancer (2002) 86, I I88- |196. DOI: 10.1038/sj/bjc/6600 I86 www.bjcancer.com

(C) 2002 Cancer Research UK

Keywords: NDGA; apoptosis; pancreatic cancer; cervical cancer; JNK; actin cytoskeleton

Arachidonic acid and its metabolites are important second messengers in the signal transduction pathways induced by receptor tyrosine kinases and $\mathrm{G}$ protein coupled receptors (Di Marzo, 1995; Rozengurt, 1998). 5-hydrocicosatetraenoic acid (5-HETE), the major 5-lipoxygenase metabolite of arachidonic acid, has been implicated as a growth promoting factor for various human cancer cells including prostate, lung and pancreatic cancer cells (Avis et al, 1996; Ghosh and Myers, 1998; Ding et al, 1999a). The resinous plant exudate nordihydroguaiaretic acid (NDGA) inhibits lipoxygenases including 5-lipoxygenases (Van Wauwe and Goossens, 1983; Chang et al, 1984). Although nordihydroguaiaretic acid (NDGA) may target other kinases (Rondeau et al, 1990; Domin et al, 1993), it has been used extensively to examine the role of the lipoxygenase pathway in the action of growth factors and cytokines (Haliday et al, 1991; Peppelenbosch et al, 1992). Indeed, NDGA blocks lipoxygenase production, inhibits growth and induces apoptosis of human lung cancer cells (Avis et al, 1996; Ghosh and Myers, 1998). In pancreatic cancer cells, NDGA inhibits thymidine incorporation and anchorage-dependent proliferation and induces apoptosis in vitro (Ding et al, 1999a,b). However, the potential mechanisms mediating these effects have not been examined. In addition, it is still unclear whether NDGA can block

*Correspondence: T Seufferlein;

E-mail: thomas.seufferlein@medizin.uni-ulm.de

Received 2 August 200 I; revised 26 November 200 I; accepted I0 January 2002 growth of various tumours in vivo. This is an important question as numerous compounds inhibit cancer cell growth in vitro but fail to be effective in vivo.

Apoptosis can be induced by many different events such as direct damage to the cell or its DNA or by the removal of survival signals provided by growth factors, cell-cell contacts and the extracellular matrix. The Raf-MEK-ERK cascade is one of the major signalling pathways promoting cell survival (Parrizas et al, 1997; Kurada and White, 1998; Anderson and Tolkovsky, 1999; Bonni et al, 1999). However, Ras-dependent cell survival is likely to require additional downstream effectors such as the PI3kinase-AKT signaling pathway (Datta et al, 1999). There is a controversy regarding the contribution of other mitogen-activated protein kinases (MAPKs) such as Jun- $\mathrm{NH}_{2}$ terminal kinase (JNKs) and $\mathrm{p} 38^{\mathrm{mapk}}$ to cell survival or apoptosis. Under certain circumstances, activation of JNKs contributes to proliferation. However, in other model systems, activation of JNKs and p38 ${ }^{\text {mapk }}$ (also known as stress activated protein kinases) can mediate apoptosis (Xia et al, 1995; Chen et al, 1996; Verheij, 1996; Zanke et al, 1996; Bossy-Wetzel et al, 1997; Behrens et al, 1999; Tournier et al, 2000). A similar role for stress activated protein kinases has been proposed for anoikis, the induction of apoptosis in epithelial cells by disruption of cell-cell and cell-matrix contacts (Frisch and Francis, 1994; Frisch et al, 1996).

Here we demonstrate that NDGA markedly inhibits growth and induces apoptosis of human pancreatic and cervical cancer cells in vitro and in vivo. NDGA did not prevent constitutive phosphorylation of $\mathrm{p} 70^{\mathrm{s} 6 \mathrm{k}}$ in these cells which regulates autonomous 
anchorage-dependent and -independent proliferation of tumour cells (Grewe et al, 1999). In addition, NDGA did not inhibit major survival pathways such as tyrosine phosphorylation of the EGFR, or TGF $\alpha$-induced activation of the ERK cascade and AKT. However, treatment of cells with NDGA leads to activation of JNKs and $\mathrm{p} 38^{\mathrm{mapk}}$, disruption of the filamentous actin cytoskeleton and cell detachment in a sequential fashion. Similar results were observed using cytochalasin D. These results provide novel information about the potential mechanisms of action of NDGA in human pancreatic and cervical cancer cells and suggest that this agent may provide a lead compound for new therapies against both cancers.

\section{MATERIALS AND METHODS}

\section{Cell culture}

Human SW 850 pancreatic (Muller et al, 1998; Taniguchi et al, 1998) and C4-I cervical cancer cells were the kind gift of W Schmiegel, Department of Internal Medicine, Medical University of Bochum, Germany. Stocks were maintained in RPMI medium supplemented with $10 \%(\mathrm{v} / \mathrm{v})$ FBS in a humidified atmosphere of $5 \% \mathrm{CO}_{2}: 95 \%$ air at $37^{\circ} \mathrm{C}$. They were passaged every 3 days.

\section{Clonogenic Assay}

SW 850 and C4-I cells were washed, trypsinised and resuspended in RPMI. Cells were then disaggregated by two passes through a 19-gauge needle into an essentially single cell suspension as judged by microscopy. Cell number was determined using a cell counting chamber and $2 \times 10^{4}$ cells were mixed with RPMI/0.5\% or $10 \%$ FBS containing $0.3 \%$ agarose in the presence or absence of NDGA at the concentrations indicated, and layered over a solid base of $0.5 \%$ agarose in $\mathrm{RPMI} / 0.5 \%$ or $10 \% \mathrm{FBS}$ in the presence or absence of NDGA at the same concentrations in $33 \mathrm{~mm}$ dishes. The cultures were incubated in humidified 5\% $\mathrm{CO}_{2}: 95 \%$ air at $37^{\circ} \mathrm{C}$ for 14 days and then stained with the vital stain nitro-blue tetrazolium. Colonies of $>120 \mu \mathrm{m}$ in diameter ( 25 cells) were counted using a microscope.

\section{Immunoprecipitations and Western blotting}

SW 850 and C4-I cells were washed twice in serum-free RPMI and incubated in fresh RPMI for further $24 \mathrm{~h}$. Cells were then treated with NDGA as indicated in the figure legends and lysed in $50 \mathrm{~mm}$ Tris- $\mathrm{HCl}, 5 \mathrm{~mm}$ EDTA, $100 \mathrm{~mm} \mathrm{NaCl}, 40 \mathrm{~mm} \beta$-glycerophosphate, $50 \mathrm{~mm} \mathrm{NaF}, 1 \mathrm{mM} \mathrm{Na} \mathrm{VO}_{4}, 1 \%$ Triton X-100, $1 \mathrm{~mm}$ phenylmethylsulphonyl fluoride, $10 \mu \mathrm{g} \mathrm{ml}^{-1}$ aprotinin, $10 \mu \mathrm{g}$ $\mathrm{ml}^{-1}$ leupeptin ( $\mathrm{pH} 7.6$, lysis buffer). For immunoprecipitations, lysates were incubated with a polyclonal anti-EGF-receptor antibody for $2 \mathrm{~h}$ at $4^{\circ} \mathrm{C}$ on a rotating wheel with protein $\mathrm{A}$ sepharose beads added for the second hour. Beads were washed twice in lysis buffer and resuspended in $2 \times$ SDS-PAGE sample buffer. Proteins were further analysed by SDS-PAGE followed by Western blotting using a monoclonal anti-Tyr(P) antibody with immunoreactive bands being visualised by enhanced chemoluminescence detection. For detection of cyclin D1, cyclin E, p $27^{\text {kip1 }}$ and $\mathrm{p} 38$ phosphorylated at $\mathrm{Thr}^{180}$ and $\mathrm{Tyr}^{182}$ and AKT phosphorylated at $\mathrm{Thr}^{308}$ cells were treated as indicated in the figure legends, lysed in SDS-PAGE sample buffer and samples were further analysed by SDS-PAGE and Western blotting with specific antisera to these proteins essentially as described above.

\section{Kinase assays}

For ERK assays serum-starved SW 850 and C4-I cells were incubated with TGF $\alpha$ or NDGA in the presence or absence of $15 \mu \mathrm{M}$ PD 098059 as indicated in the figure legends. Controls received an equivalent amount of solvent. Cells were then lysed at $4{ }^{\circ} \mathrm{C}$ in $1 \mathrm{ml}$ RIPA buffer (150 mM NaCl, 1\% NP-40, 1\% DOC, $0.1 \%$

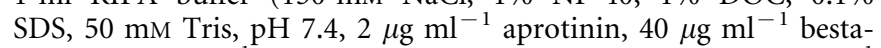
tin, $\quad 0.5 \mu \mathrm{g} \mathrm{ml}^{-1}$ leupeptin, $0.5 \mathrm{mM}$ AEBSF, $0.7 \mu \mathrm{g} \mathrm{ml}^{-1}$ pepstatin). Immunoprecipitations were performed at $4^{\circ} \mathrm{C}$ using an anti-ERK1/2 antibody for $2 \mathrm{~h}$ with protein $\mathrm{A}$ agarose added for the second hour. Immune complexes were washed three times in lysis buffer and once with ERK kinase buffer (15 mM $\mathrm{MgCl}_{2}$, $15 \mathrm{~mm}$ Tris- $\mathrm{HCl}, \mathrm{pH}$ 7.4). Kinase reactions were performed by resuspending the protein A sepharose pellets in $25 \mu \mathrm{l}$ of kinase assay mixture containing the appropriate kinase buffer with $0.2 \mu \mathrm{M}$ MBP, $20 \mu \mathrm{M}$ ATP, $5 \mu \mathrm{Ci} \mathrm{ml}^{-1}\left[\gamma_{-}{ }^{32} \mathrm{P}\right] \mathrm{ATP}, 2 \mu \mathrm{M}$ cAMPdependent protein kinase inhibitor peptide and $100 \mathrm{nM}$ microcystin LR. Incubations were performed under linear assay conditions at $30^{\circ} \mathrm{C}$ for $20 \mathrm{~min}$ and terminated by adding $20 \mu \mathrm{l}$ of $5 \times$ SDSsample buffer. Samples were boiled for $10 \mathrm{~min}$ at $95^{\circ} \mathrm{C}$ and proteins were separated by SDS - PAGE followed by autoradiography. For JNK and $\mathrm{p} 38^{\text {mapk }}$ cells were washed with PBS and lysed in $20 \mathrm{mM}$ HEPES pH 7.4, $2 \mathrm{mM}$ EGTA, $50 \mathrm{~mm} \beta$-glycerophosphate, $1 \mathrm{mM}$ DTT, $1 \mathrm{mM} \mathrm{Na} \mathrm{VO}_{4}, 10 \%$ glycerol, $1 \%$ Triton X-100, $2 \mu \mathrm{M}$ leupeptin, $0.5 \mathrm{mM}$ AEBSF, $5 \mu \mathrm{g} \mathrm{ml}^{-1}$ aprotinin, $0.1 \mu \mathrm{g} \mathrm{ml}^{-1}$ okadaic acid. After $5 \mathrm{~min}$ on ice, the lysate was clarified and immunoprecipitated with the respective antibodies. The immunoprecipitates were washed thrice each in lysis buffer and finally in assay buffer (JNK: $20 \mathrm{~mm}$ MOPS pH 7.2, 2 mM EGTA, $10 \mathrm{~mm}$ $\mathrm{MgCl}_{2}, 1 \mathrm{mM}$ DTT, $0.1 \%$ Triton X-100; p38: $20 \mathrm{~mm}$ MOPS, pH 7, 1 mM EDTA, 5\% glycerol, $0.1 \% \beta$-mercaptoethanol, $0.01 \%$ Brij 35, $0.1 \mu \mathrm{g} \mathrm{ml}^{-1}$ okadaic acid). Kinase reactions contained $20 \mu \mathrm{l}$ kinase buffer with $1 \mu \mathrm{g}$ of either ATF2- or cJun-GST fusion protein and Mg-ATP mixes as follows: JNK, $7.5 \mu \mathrm{l} 50 \mathrm{mM} \mathrm{MgCl}_{2}$, $100 \mu \mathrm{M}$ ATP, $2 \mu \mathrm{Ci}\left[\gamma_{-}{ }^{32} \mathrm{P}\right] \mathrm{ATP}$; p38 ${ }^{\mathrm{mapk}}, 6 \mu \mathrm{l} 60 \mathrm{mM} \mathrm{Mg}$ acetate, $300 \mu \mathrm{M}$ ATP and $2 \mu \mathrm{Ci}\left[\gamma-{ }^{32} \mathrm{P}\right] \mathrm{ATP}$. After $20 \mathrm{~min}$ at $30^{\circ} \mathrm{C}$, the reactions were stopped by addition of $5 \times$ SDS-PAGE sample buffer and further analysed as described above. GST-cJun and GST-ATF2 fusion proteins were prepared essentially as described (Seufferlein et al, 1999).

\section{p70 ${ }^{\text {s6k }}$ mobility shift assays}

Activation of $\mathrm{p} 70^{\mathrm{s} 6 \mathrm{k}}$ by mitogens can be determined by the appearance of slower migrating forms in SDS-PAGE due to phosphorylation of $\mathrm{p} 70^{\text {s6k }}$ on $\mathrm{Thr}^{229}$ and $\mathrm{Thr}^{389}$ and $\mathrm{Ser}^{404}$ which are not phosphorylated in quiescent cells (Ferrari and Thomas, 1994). For p70 $0^{\text {s6k }}$ mobility shift assays cells were treated as indicated in the figure legends and lysed in SDS-PAGE sample buffer. Samples were further analysed by SDS - PAGE and Western blotting with a specific anti-p70 $70^{\text {s6k }}$ antibody.

\section{In situ detection of apoptotic cells}

DNA fragmentation was measured by catalytically incorporating fluorescein-12-dUTP at the $3^{\prime}-\mathrm{OH}$ DNA ends using the enzyme TdT according to the principle of the TUNEL assay. To detect apoptosis in tumour xenografts paraffin-embedded tissue sections of the tumours were deparaffinised and rehydrated through graded ethanol washes, fixed in $4 \%$ methanol-free formaldehyde, treated with $20 \mu \mathrm{g} \mathrm{ml}^{-1}$ proteinase $\mathrm{K}$ solution for $8-10 \mathrm{~min}$, fixed again and further processed according to the manufacturer's protocol.

\section{Tumour growth in athymic mice}

$1.5 \times 10^{6}$ SW 850 or $2 \times 10^{6}$ C4-I cells were inoculated subcutaneously into both flanks of 4-6 week old female athymic NMRI/ nu-nu mice and the mice were maintained in a pathogen-free environment. The animals were observed daily for tumour development. When measurable tumours were established $\left(>15 \mathrm{~mm}^{3}\right)$, the animals were randomised into two groups of six animals. One group received $750 \mu \mathrm{g}$ NDGA (corresponding to about $90 \mu \mathrm{M}$ 
NDGA (w/v)) in $0.1 \mathrm{ml}$ of a solution containing $90 \%$ sterile $\mathrm{H}_{2} \mathrm{O}$ and $10 \%$ ethanol i.p. $5 \times$ per week. The control animals received an equivalent amount of solvent i.p. Tumour size was measured twice weekly and mice were killed after 3 weeks of treatment. Growth curves for xenografts were determined by externally measuring the length, height and width of the tumours, and the volume was calculated according to the following equation: volume $=($ length $\times$ height $\times$ width $) \times 0.5$. To examine statistical significance an univariate Students $t$-test was performed.

\section{Materials}

NDGA was obtained from FLUKA/Sigma-Aldrich (Deisenhofen, Germany). Antibodies against p70 ${ }^{\mathrm{s} 6 \mathrm{k}}, \mathrm{p} 27^{\mathrm{kip} 1}$, cyclin D1, cyclin E, JNK1/2, p38 ${ }^{\text {mapk }}$, and the EGFR were obtained from Santa Cruz Biotechnology (Santa Cruz, USA). The phospho-specific antip3 $8^{\text {mapk }}$ and anti-AKT antibodies were from New England Biolabs (Schwalbach/Taunus, Germany). Protein A sepharose was obtained from Boehringer Mannheim (Mannheim, Germany). ECL-reagent and $\left[\gamma_{-}{ }^{32} \mathrm{P}\right]$-ATP were obtained from Amersham/Pharmacia (Freiburg, Germany). The apoptosis detection system fluorescein was from Promega (Mannheim, Germany). Oregon-green labelled phalloidin was obtained from Molecular Probes (Leiden, Netherlands). MBP was from Sigma (Deisenhofen, Germany). All other reagents were of the purest grade available.

\section{RESULTS}

\section{NDGA delays growth of tumours established in athymic mice}

To establish whether NDGA could indeed inhibit tumour growth in vivo we first examined a panel of various epithelial cancer cell lines for their ability to consistently induce xenograft tumours in nude mice. Among these tumour cell lines, SW 850 human pancreatic cancer cells and C4-I human cervical cancer cells induced tumour xenografts in athymic mice most consistently and were therefore used for all subsequent experiments (data not shown). Tumours were established by subcutaneous injection of SW 850 and C4-I cells to both flanks of athymic mice. When the tumour volume was $15 \mathrm{~mm}^{3}$, mice were treated with five times per week i.p. injections of NDGA or diluent for 3 weeks. As shown in Figure 1A, treatment with NDGA delayed the growth of both SW 850 and C4-I tumours by about 50\%. The compound was very well tolerated by the animals. No side effects or behavioural abnormalities were observed during the course of treatment. There were no marked differences in body weight of the animals treated with NDGA or with solvent during the course of treatment despite the fact that the animals treated with solvent had bigger tumours. In animals injected with SW 850 cells, body weight in the control group was $21.5 \pm 1.8 \mathrm{~g}$ at the beginning and $24 \pm 1.3 \mathrm{~g}$ at the end of the treatment. In the NDGA group body weight of the animals was $23.3 \pm 1.2 \mathrm{~g}$ at the beginning and $24.3 \pm 1.4 \mathrm{~g}$ at the end of the treatment. The corresponding figures in the animals injected with C4-I cells were $27.5 \pm 2.1 \mathrm{~g}$ and $29.8 \pm 1.7 \mathrm{~g}$ in the control group and $27.5 \pm 2 \mathrm{~g}$ and $29.2 \pm 2.1 \mathrm{~g}$ in the NDGA group, respectively.

\section{NDGA inhibits anchorage-independent growth of SW 850 and C4-I cancer cells}

In addition to its effect on tumour growth in vivo we examined the effect of NDGA on colony formation of SW 850 and C4-I cells in soft agar, a useful in vitro-test to judge the efficacy of a compound as a potential anticancer agent (Carney et al, 1980). NDGA potently inhibited colony formation in response to both $0.5 \%$ FBS and 10\% FBS, which induced maximum clonogenic growth in SW 850 and C4-I cells (Figure 1B). Thus, NDGA is a potent inhibitor of anchorage-independent growth in SW 850 and C4-I
A

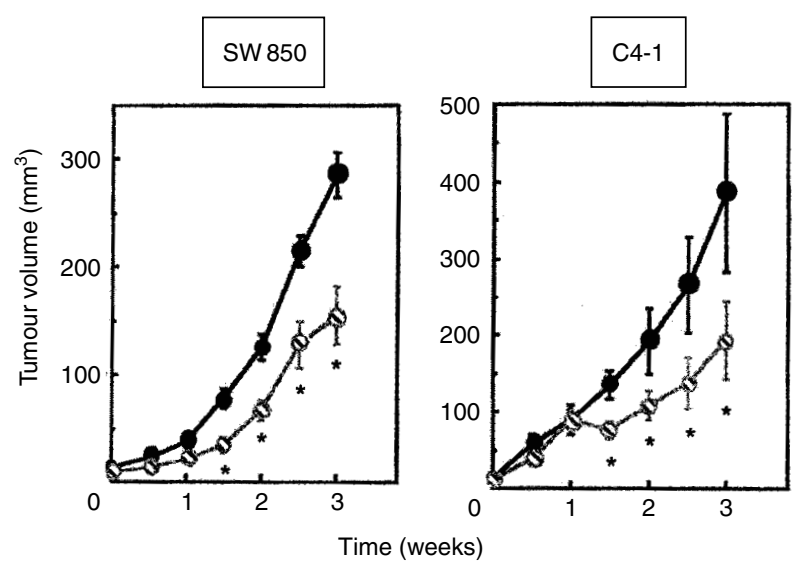

B

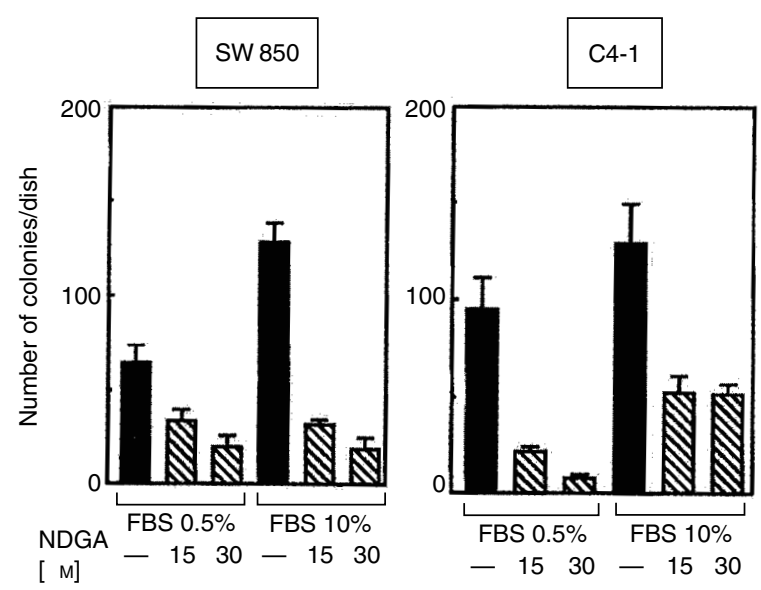

Figure I (A) NDGA delays growth of xenograft tumours established in athymic mice A: $1.5 \times 10^{6} \mathrm{SW} 850$ or $2 \times 10^{6} \mathrm{C} 4-$ - cells were inoculated subcutaneously into both flanks of $4-6$ week old female athymic NMRI/ nu-nu mice and the mice were maintained in a pathogen-free environment. When measurable tumours were established $\left(>15 \mathrm{~mm}^{3}\right)$, the animals were randomised into two groups of six animals and treated as described in Materials and Methods. Growth curves for xenografts were determined by externally measuring the length, height and width of the tumours at the days indicated. The tumour volume was calculated according to the following equation: volume $=($ length $\times$ height $\times$ width $) \times 0.5$. Values are the means \pm SE $(n=6)$. Mice were sacrificed after 3 weeks of treatment with $750 \mu$ NDGA $5 \times$ per week i.p. * Indicates a statistically significant difference in tumour size between the NDGA group and the control group $(P<0.05)$. (B) NDGA inhibits colony growth in SW 850 and $C 4-1$ cells (A) Single cell suspensions of SW 850 (left panel), or C4-I cells (right panel) were plated at a density of $3 \times 10^{4}$ cells/dish in agarose medium containing RPMI and $0.5 \%$ (left) or I0\% FBS (right) and various concentrations of NDGA as indicated. Colonies were counted after 2 weeks of incubation. In all cases, a representative of two independent experiments each performed in triplicates is shown.

cells even in the presence of maximum stimulatory concentrations of FBS.

NDGA has previously been reported to inhibit thymidine incorporation and anchorage-dependent proliferation in human pancreatic cancer cells (Ding et al, 1999a). We confirmed these observations in SW 850 and also in C4-I cervical cancer cells (data not shown). Interestingly, we observed that as early as $8 \mathrm{~h}$ after treatment with NDGA, cells started to detach from the tissue culture dishes making it difficult to determine whether the reduction in thymidine incorporation and cell numbers observed in response to NDGA were due to inhibition of DNA synthesis rather than cell detachment. 
NDGA induces apotosis of SW 850 and C4-I cancer cells in vitro and in vivo

NDGA has been reported to induce apoptosis in certain cancer cells in vitro. Indeed, NDGA induced apoptosis in SW 850 pancreatic cancer cells and also in C4-I human cervical cancer cells as judged by TUNEL assays (Figure 2A). Upon treatment of cells with $25 \mu \mathrm{M}$ NDGA for $12 \mathrm{~h}$, the proportion of cells exhibiting fragmented DNA markedly increased from 2 to $34 \%$ in SW 850 and from 0 to $26 \%$ in C4-I cells. The apoptosis-inducing effect of NDGA was

A
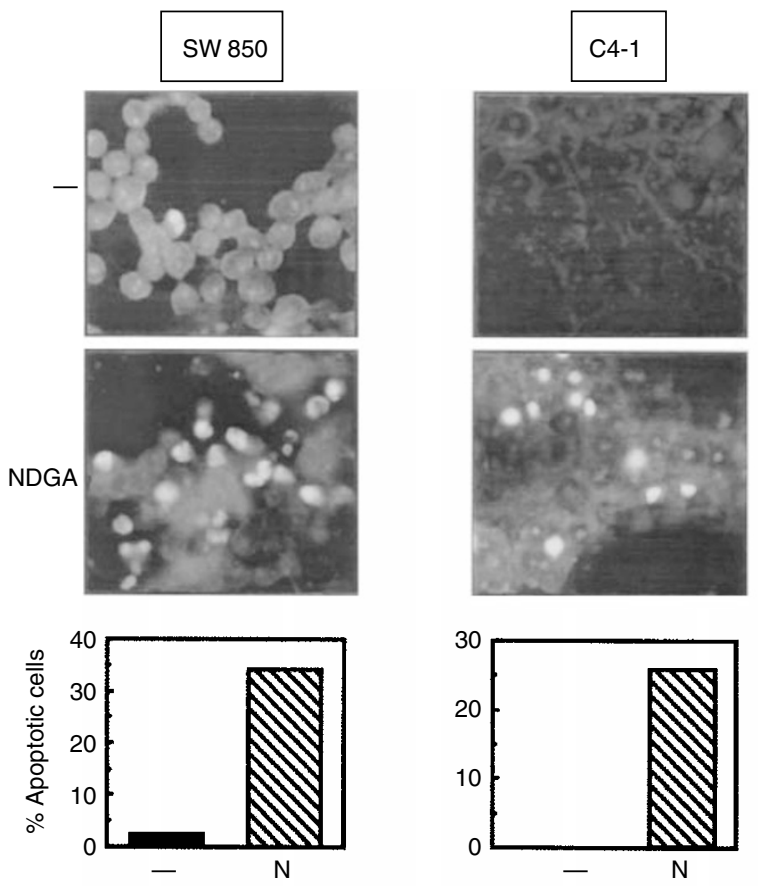

B
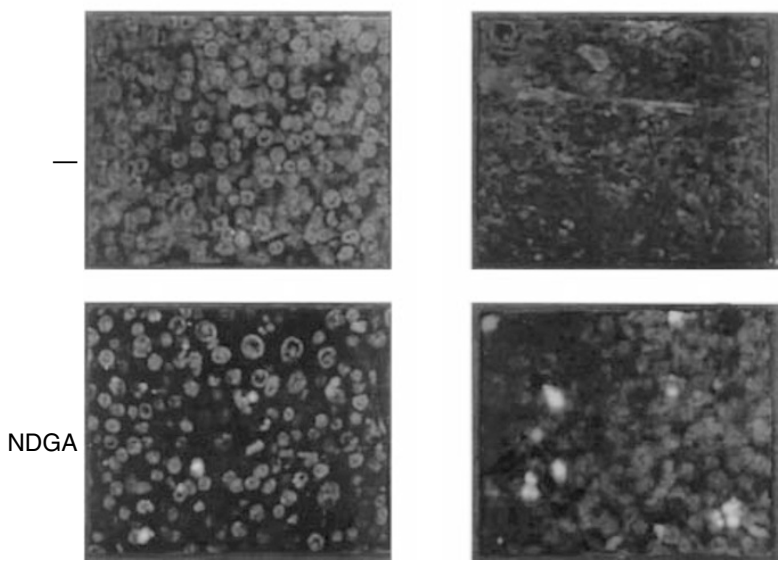

Figure 2 NDGA induces apoptosis in SW 850 and C4-I cells in vitro and in vivo. (A) Upper panels: SW 850 (left) and C4-I cells were incubated with $25 \mu \mathrm{M}$ NDGA for $18 \mathrm{~h}$ and DNA fragmentation was determined by in situfluorescence TUNEL assays as described in Materials and Methods. Lower panels: The proportion of TUNEL positive cells was counted in four independent microscopic fields ( $N=$ NDGA). (B) Paraffin sections of tumour xenografts (left SW 850, right C4-I) obtained from mice treated with NDGA (NDGA) or solvent (-) were analysed by an in situ-fluorescence TUNEL assay to detect DNA fragmentation as described in Materials and Methods. Apoptotic cells are characterised by a strong fluorescence within the nucleus corresponding to labelling of fragmented DNA. first detectable after $3 \mathrm{~h}$ of incubation and reached a maximum after $12-16 \mathrm{~h}$ of incubation (data not shown). To examine whether NDGA induced similar molecular mechanisms in the pancreatic and cervical xenograft tumours in vivo, paraffinembedded tissue sections of tumours obtained from animals treated with NDGA or with solvent were examined by in situfluorescence TUNEL assays. Treatment of mice with NDGA led to a marked increase in the number of apoptotic cells in tumours established from SW 850 and C4-I cells (Figure 2B). Thus, NDGA induces apoptosis in pancreatic and cervical tumours in vitro and in vivo.

\section{NDGA does not inhibit growth and survival signals in SW 850 and C4-I cells}

Next, we were interested in potential mechanisms mediating the growth inhibitory effect of NDGA in human pancreatic and cervical cancer cells. NDGA has been shown to inhibit tyrosine phosphorylation of certain receptor tyrosine kinases (Domin et $a l, 1993)$. The EGFR and its respective ligands such as TGF $\alpha$ trigger growth and prevent apoptosis by autocrine and/or paracrine mechanisms in many cancer cell lines (Korc et al, 1992; Bonni et al, 1999; Seufferlein et al, 1999). To examine whether NDGA could inhibit tyrosine phosphorylation of the EGFR, serum starved SW 850 and C4-I cells were treated with TGF $\alpha$ in the absence or presence of NDGA and autophosphorylation of the EGFR was determined by anti-Tyr(P) Western blotting. NDGA had no effect on TGF $\alpha$-induced tyrosine phosphorylation of the EGFR in SW 850 and C4-I cells, respectively (Figure 3A). Similar data were obtained for insulin-like growth factor I-induced phosphorylation of the IGF-I receptor (data not shown).

Activity of the serine-threonine kinase $\mathrm{p} 70^{\mathrm{s} 6 \mathrm{k}}$ is important for progression from the G1 to the $\mathrm{S}$ phase of the cell cycle (Chou and Blenis, 1995). We have recently demonstrated that the FRAP-p $70^{\text {s6K }}$ pathway is constitutively active in human pancreatic cancer cells and regulates autonomous growth of these cells (Grewe et al, 1999). As shown in Figure 3B, NDGA did not substantially inhibit basal phosphorylation of $\mathrm{p} 70^{\mathrm{s} 6 \mathrm{k}}$. NDGA treatment of SW 850 cells also did not markedly interfere with further phosphorylation of $\mathrm{p} 70^{\mathrm{s} 6 \mathrm{k}}$ in response to TGF $\alpha$. In contrast, treatment of cells with the selective inhibitor of the FRAP-p70 $0^{\mathrm{s} 6 \mathrm{k}}$ pathway, rapamycin (Brown et al, 1995), prevented both, basal and TGF $\alpha$-stimulated phosphorylation of $\mathrm{p}^{\mathrm{s} 6 \mathrm{k}}$ (Figure $3 \mathrm{~B}$ ). Similar results were obtained in the C4-I cell line (data not shown).

Ras activates two major survival pathways, the ERK cascade and AKT (Anderson and Tolkovsky, 1999; Bonni et al, 1999; Datta et al, 1999). NDGA did not inhibit phosphorylation of the antiapoptotic protein kinase AKT in TGF $\alpha$-stimulated $\mathrm{C} 4$-I cells. In contrast, inhibition of the major upstream regulator of AKT, PI3-kinase, by the selective PI3-kinase inhibitor LY294002 markedly prevented TGF $\alpha$-stimulated AKT phosphorylation in C4-I cells (Figure 3C). Similar data were obtained in SW 850 cells (data not shown). NDGA had also no effect on basal and TGF $\alpha$-stimulated activation of ERK1/2. In contrast, the selective MEK-1 inhibitor PD 098059 inhibited both basal and TGF $\alpha$-stimulated activation of ERK1/2 (Figure 3D). These data demonstrate that NDGA does not act as an inhibitor of the EGFR kinase or the activation of the Ras/Raf/ERK- or the Ras/PI3-kinase/AKT/p70 $0^{\text {s6k }}$ signalling pathways in pancreatic and cervical cancer cells.

\section{NDGA inhibits expression of cyclin D1 in SW 850 and C4-I human cancer cells}

Thus, inhibition of tumour cell growth by NDGA could not be explained by inhibition of the major growth promoting intracellular signalling pathways in response to NDGA. Therefore, we reasoned that this compound could directly affect the regulation of the cell cycle machinery. In particular, cyclin D1 is a major regu- 
A

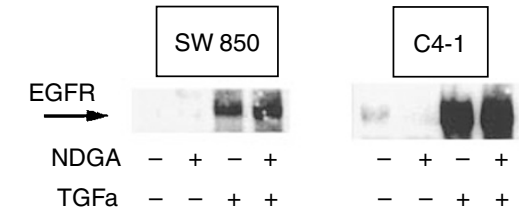

B

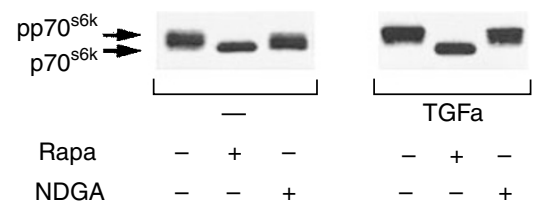

C

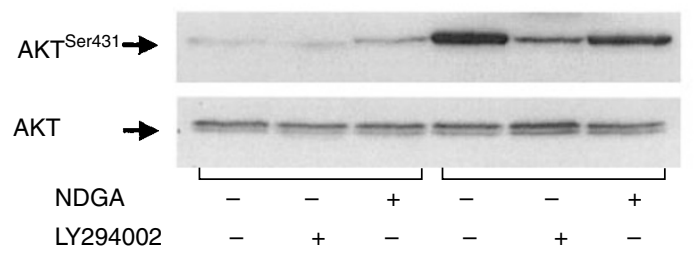

D

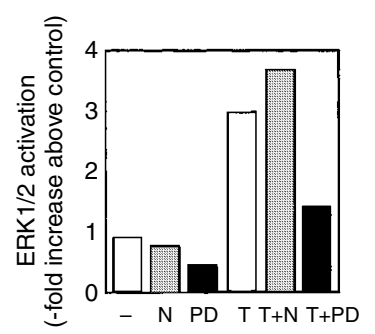

E

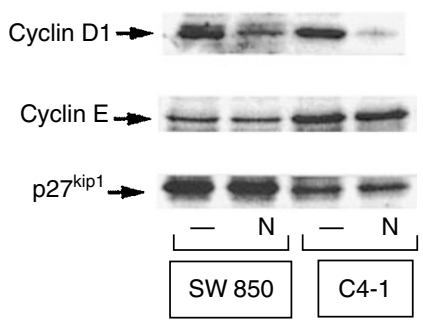

Figure 3 (A) TGF $\alpha$-induced tyrosine phosphorylation of the EGFR in SW 850 and C4-I cells is not affected by NDGA treatment of cells. Serum starved SW 850 (left) or C4-I cells (right) were treated for 60 min with $25 \mu \mathrm{M}$ NDGA $(+)$. Control cells received an equivalent amount of solvent

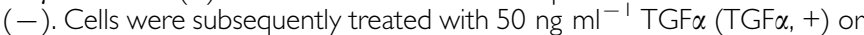
an equivalent amount of solvent ( - ) for 10 min. Cells were then lysed and tyrosine phosphorylation of the EGFR was further analysed as described in Materials and Methods. (B) NDGA does not inhibit constitutive and TGF $\alpha$ stimulated phosphorylation of p70 s6k in SW 850 cells. Serum-starved cultures of SW 850 cells were treated for $15 \mathrm{~min}$ with $50 \mathrm{ng} \mathrm{ml}{ }^{-1}$ TGF $\alpha$ in the absence $(-)$ or presence of $30 \mu \mathrm{M}$ NDGA (NDGA, +) or $20 \mathrm{ng} \mathrm{ml}^{-1}$ rapamycin (Rapa, + ) or received an equivalent amount of solvent $(-)$. p $70^{56 k}$ mobility shift assays were performed as described in Materials and Methods. The results shown in each case are representative of three independent experiments. The positions of hypophosphorylated $p 70^{s 6 k}\left(p 70^{s 6 k}\right)$ and the slower migrating phosphorylated $p 70^{s 6 k}\left(p p 70^{s 6 k}\right)$ are indicated by arrows. (C) NDGA does not inhibit basal and TGF $\alpha$-stimulated activation of AKT. Serum-starved cultures of C4-I cells were treated for $15 \mathrm{~min}$ with $50 \mathrm{ng} \mathrm{ml}{ }^{-1}$ TGFa in the absence $(-)$ or presence of $30 \mu \mathrm{M}$ NDGA (+) or $20 \mu \mathrm{M}$ LY294002 (+) or received an equivalent amount of solvent $(-)$. Phosphorylation of AKT at Ser ${ }^{431}$ was determined using an activation-specific antibody as described in Materials and Methods and is indicated by an arrow (AKT ${ }^{\text {Ser43I }}$ ). The same samples were also analysed using a pan-AKT antibody. The position of AKT is indicated by an arrow. (D) NDGA does not inhibit basal and TGF $\alpha$-stimulated activation of ERK I/2: Serum-starved cultures of C4-I cells were treated for 15 min with $50 \mathrm{ng} \mathrm{ml}{ }^{-1}$ TGF $\alpha(\mathrm{T})$ in the absence $(-)$ or presence of $25 \mu \mathrm{M}$ NDGA (N) or $15 \mu \mathrm{M}$ PD 098059 (PD) or received an equivalent amount of solvent $(-)$. ERKI/2 immune complex kinase assays were performed as described in Materials and Methods. (E) NDGA inhibits constitutive cyclin DI expression in SW 850 and C4-I cancer cells: Subconfluent cultures of SW 850 and C4-I cells were treated with $25 \mu \mathrm{M}$ NDGA (N) for $18 \mathrm{~h}$. Control cells received an equivalent amount of solvent $(-)$. Cells were lysed and further analysed by Western blotting with either anti-cyclin DI, anti-cyclin E or anti-p27 $7^{\text {kip I }}$ antibodies as indicated by an arrow. The results shown in each case are representative of at least three independent experiments. lator of proliferation at the level of the cell cycle (Sherr, 1993) and is overexpressed in many cancers (Weinstein, 1996). In pancreatic cancer, overexpression of cyclin D1 is associated with increased aggressiveness of these tumours (Kornmann et al, 1998). We have previously shown that cyclin D1 and E but also cyclin-dependent kinase inhibitors such as p2 $7^{\text {kip } 1}$ are constitutively expressed in human pancreatic cancer cells (Grewe et al, 1999). As shown in Figure $3 \mathrm{E}$, cyclin D1, cyclin E and p27 ${ }^{\mathrm{kip} 1}$ were also constitutively expressed in C4-I human cervical cancer cells. Incubation of cells with NDGA resulted in a marked reduction in the expression of cyclin D1 in both cell lines whereas the levels of expression of cyclin $\mathrm{E}$ and $\mathrm{p} 27^{\mathrm{kip} 1}$ remained unchanged. These results suggest that the inhibition of proliferation in response to NDGA in SW 850 and C4-I cells could, at least in part, be mediated by inhibition of cyclin D1 expression.

\section{NDGA and cytochalasin D induce depolymerisation of the actin cytoskeleton in SW 850 and C4-I cells}

The actin cytoskeleton in concert with adhesion molecules controls cell-cell and cell-substrate interactions and participates in transmembrane signalling. Upon treatment of cells with NDGA we observed substantial cell detachment. This could be a consequence of the induction of apoptosis, but also due to a more direct effect of NDGA on the cytoskeleton in pancreatic and cervical cancer cells. To examine the effect of NDGA on the actin cytoskeleton in SW 850 and C4-I cells, actin was analysed by immunofluorescence using Oregon-green-labelled phalloidin after treatment of cells with NDGA or solvent. As shown in Figure 4 (top panels), control cells exhibited a well developed actin cytoskeleton with a circumferential actin filament network, actin microspikes at the plasma membrane and actin stress fibres crossing the cells. Strikingly, within $30 \mathrm{~min}$ of exposure to $25 \mu \mathrm{M}$ NDGA, actin stress fibers disappeared and the number of mikrospikes was markedly reduced. A maximum effect of NDGA on the actin cytoskeleton was observed after 60 min of incubation (Figure 4, middle panels) and clearly preceded cell detachment and the induction of apoptosis in response to NDGA (data not shown). Interestingly, cortical actin filaments were less affected by the NDGA treatment (Figure 4 , middle panels). The effect of NDGA on the filamentous actin cytoskeleton was comparable to that of cytochalasin D. However, in addition to the disruption of actin stress fibres, cytochalasin D
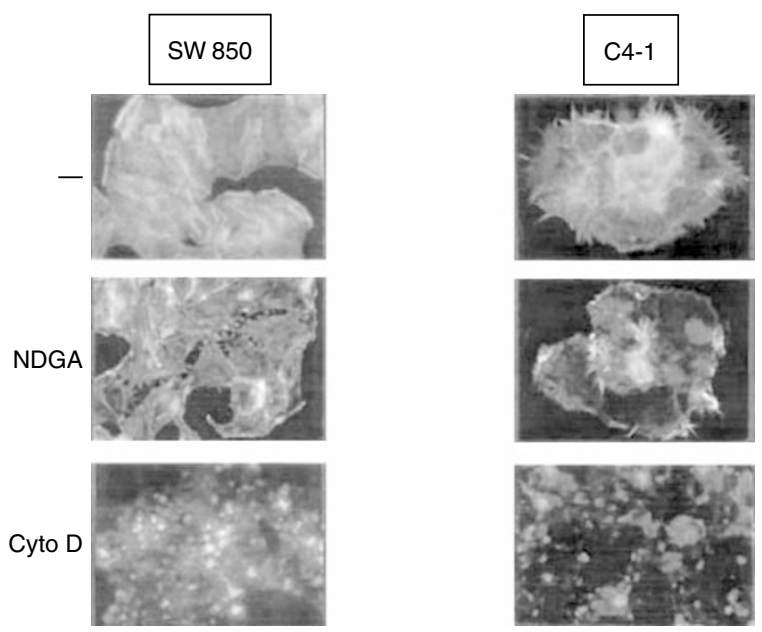

Figure 4 NDGA and cytochalasin D induce breakdown of the actin cytoskeleton. Serum starved SW 850 (left) and C4-I cells (right) were treated with $25 \mu \mathrm{M}$ NDGA (NDGA) or $2 \mu \mathrm{M}$ cytochalasin D (Cyto D) for $60 \mathrm{~min}$ or received an equivalent amount of solvent $(-)$. Cells were subsequently fixed and actin was further analysed by immunocytochemistry as described in Materials and Methods. 
A

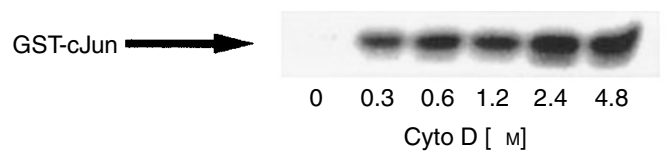

B
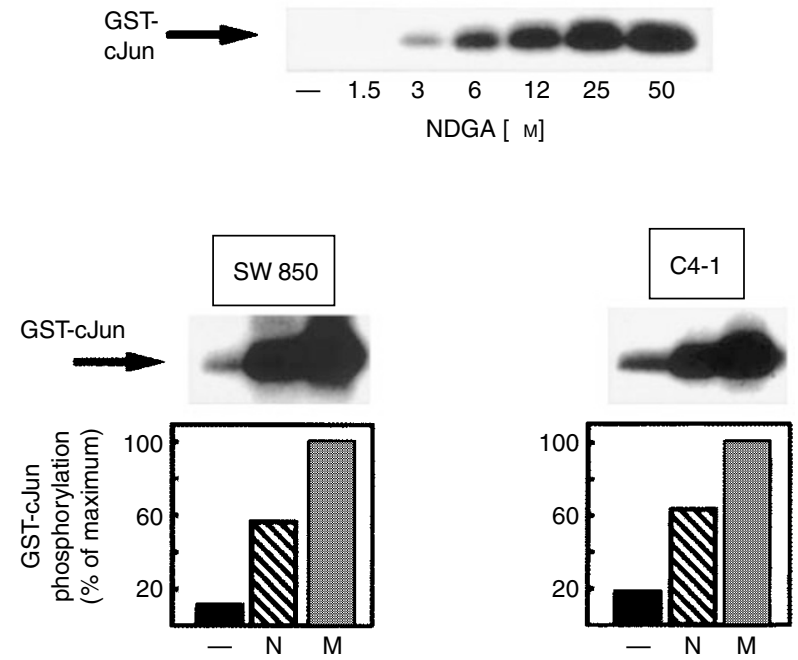

C
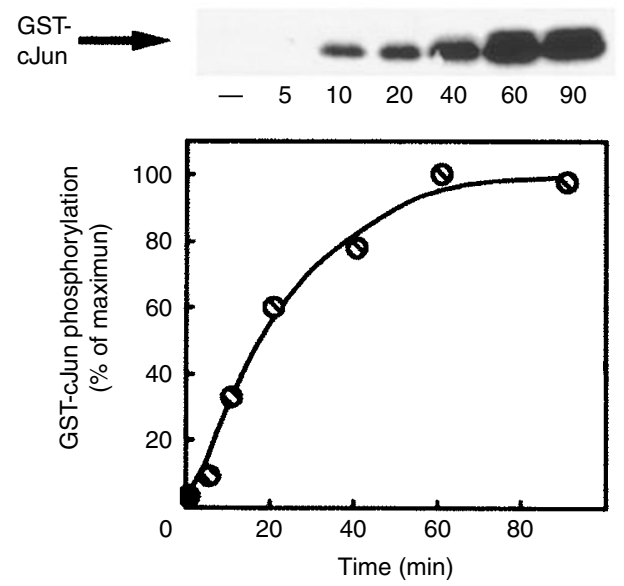

Figure 5 (A) Cytochalasin D activates of JNKI/2 in SW 850 and C4-I cells: Top panel: SW 850 cells were incubated with various concentrations of cytochalasin D (Cyto D) for 60 min as indicated. Control cells received an equivalent amount of solvent. JNK activity was determined in JNK-immune complex kinase assays using a GST-cJun fusion protein as substrate as described in Materials and Methods. The position of the GST-cJun fusion protein is indicated by an arrow. (B) NDGA induces activation of JNKI/2 in SW 850 and C4-I cells. Top panel: Concentration dependence of NDGAinduced JNK activation. C4-I cells were incubated with various concentrations of NDGA for $60 \mathrm{~min}$ as indicated. Control cells received an equivalent amount of solvent. Cells were further analysed by JNKI/2-immune complex kinase assays using GST-c)un as substrate. Middle and bottom panels: SW 850 (left) and C4-I cells (right) were incubated with $25 \mu \mathrm{M}$ NDGA (N) or I mM mannitol (M) for 60 min or received an equivalent amount of solvent $(-)$. Cells were subsequently analysed by JNK-immune complex kinase assays as described in Materials and Methods. The experiments shown are representative of at least three independent experiments. Results from a representative experiment were subjected to scanning densitometry. The data are expressed as per cent of maximal GST-clun phosphorylation obtained in response to I mM mannitol in both cell lines. (C) Kinetics of NDGA-induced activation of JNKI/2. Top: Serum starved SW 850 cells were treated with $25 \mu \mathrm{M}$ NDGA for various times as indicated also disrupted the circumferential actin filament network (Figure 4, bottom panels). The effect of cytochalasin $\mathrm{D}$ on the actin cytoskeleton in SW 850 and C4-I cells was first visible at $0.3 \mu \mathrm{M}$ and reached a maximum at $2 \mu \mathrm{M}$ cytochalasin D. At these concentrations, cytochalasin D also induced apoptosis in both cell lines (data not shown). These data suggest that NDGA by inhibiting the organisation of actin stress fibers in SW 850 and C4-I cells interferes with cell-matrix interaction and induces anoikis.

\section{NDGA and cytochalasin D activate stress-activated protein kinases in SW 850 and C4-I cells}

Anoikis by detachment of epithelial cells from their matrix is associated with the activation of Jun- $\mathrm{NH}_{2}$-terminal kinases (Frisch et al, 1996). Treatment of SW 850 and C4-I cells with cytochalasin $\mathrm{D}$ also induced JNK1/2 activation in a concentration dependent manner reaching a maximum at $2.4 \mu \mathrm{M}$ cytochalasin $\mathrm{D}$ in both cell lines (Figure 5A and data not shown). Interestingly, NDGA also induced a dose dependent activation of JNK1/2 in both cell lines with a maximum effect at $25 \mu \mathrm{M}$ (Figure $5 \mathrm{~B}$, top panel and data not shown). In both cell lines, GST-cJun phosphorylation in response to NDGA was about $60 \%$ of that in response to $1 \mathrm{mM}$ mannitol, a potent osmotic stressor (Kyriakis and Avruch, 1996) (Figure 5B, bottom panels). Furthermore, NDGA induced phospho-JNK immunoreactivity exclusively in the nucleus of SW 850 and C4-I cells treated with NDGA providing additional evidence that NDGA is a strong activator of JNKs (Cavigelli et al, 1995; Sanchez-Perez et al, 1998; data not shown).

Figure 5C shows the kinetics of NDGA-induced JNK1/2 activation. Activation of JNK1/2 in response to NDGA was detectable as early as 10 min following treatment of SW 850 and C4-I cells with $25 \mu \mathrm{M}$ NDGA; a maximum effect was obtained after $60 \mathrm{~min}$ of incubation.

NDGA did not affect the activation of the non-stress related members of the MAPK family ERK1/2 in cancer cell lines examined. In marked contrast, the results in Figure 6A demonstrate that NDGA activates the stress related $\mathrm{p} 38^{\text {mapk }}$ in immune complex kinase assays reaching 60 and $50 \%$ of mannitol-induced GST-ATF2 phosphorylation in SW 850 and C4-I cells, respectively. Activation of $\mathrm{p} 38^{\text {mapk }}$ occurs upon dual phosphorylation at $\mathrm{Thr}^{180}$ and $\mathrm{Tyr}^{182}$ (Han et al, 1994). Using an antibody which specifically detects phosphorylation of the kinase at these two residues, p3 $8^{\text {mapk }}$ phosphorylation was first detectable at about $2 \mu \mathrm{M}$ NDGA reaching a maximum at $15 \mu \mathrm{M}$ NDGA in C4-I and SW 850 cells (Figure 6B, top panel and data not shown). p3 $8^{\text {mapk }}$ phosphorylation could be detected as early as 5 min after incubation with NDGA reaching a maximum after $30 \mathrm{~min}$ of incubation (Figure 6B, bottom panel and data not shown). Thus, NDGA selectively activates the stress-activated protein kinases of the MAPK family.

\section{DISCUSSION}

A better understanding of the biology of tumours could greatly improve our current concepts of cancer therapy. Arachadonic acid and its metabolites such as 5-HETE have been implicated as growth promoting factors for various human cancers (Avis et al, 1996; Ghosh and Myers, 1998; Ding et al, 1999a). Here, we demonstrate that the resinous plant exsudate NDGA, a 5-lipoxygenase inhibitor, markedly inhibits anchorage-independent growth of human pancreatic and cervical cancer cells in serum as well as growth of xenograft tumours established from these cells in athy-

and JNKI/2-immune complex kinase assays were performed as described in Materials and Methods. A typical result in SW 850 cells was subjected to scanning densitometry. Data are expressed as per cent of maximal JNK I/2 activation obtained after 60 min of incubation. 
A

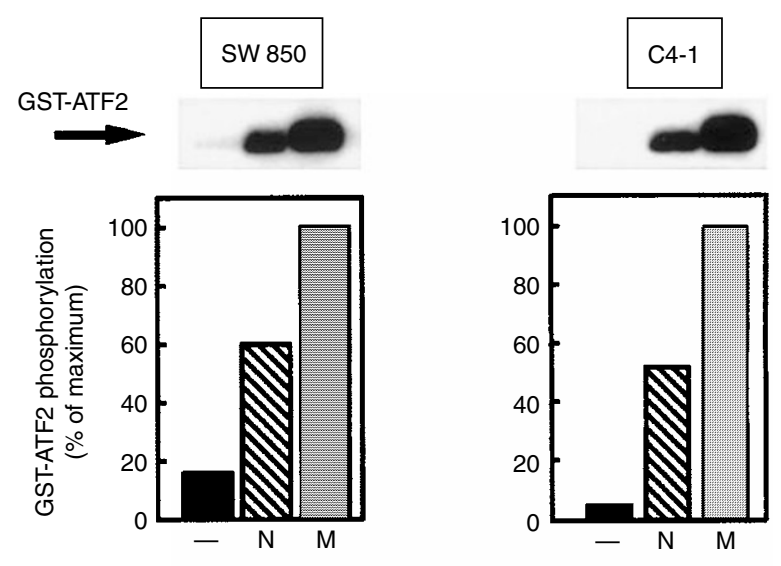

B
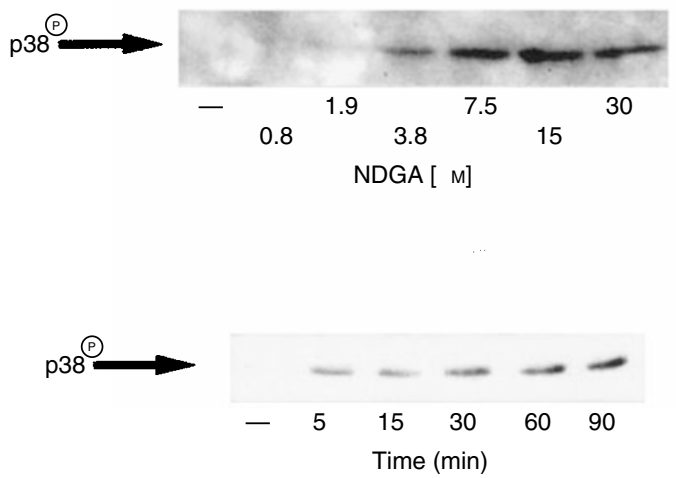

Figure 6 NDGA selectively stimulates p38 $8^{\text {mapk }}$ activation in SW 850 and C4-I cells. (A) Top: SW 850 and C4-I cells were incubated with $25 \mu \mathrm{M}$ NDGA (N) or I mM mannitol (M) for 60 min. Control cells received an equivalent amount of solvent $(-)$. Cells were further analysed by p38mapk immune complex kinase assays using a GST-ATF2 fusion protein as substrate. (A) Bottom panels: Typical results of $\mathrm{p} 38^{\mathrm{mapk}}$ immune complex kinase assays in SW 850 (left) and C4-I cells (right) were subjected to scanning densitometry. Data are expressed as per cent of maximal GSTATF2 phosphorylation obtained in response to I mM mannitol. (B) Top panel: Serum starved SW 850 cells were incubated with various concentrations of NDGA for $60 \mathrm{~min}$ and further analysed by Western blotting using a phosphospecific anti-p38 $8^{\text {mapk }}$ antibody as described in Materials and Methods. (B) Bottom panel: Serum starved C4-I cells were incubated with $25 \mu \mathrm{M}$ NDGA for various times and further analysed by Western blotting using a phosphospecific anti-p38 $8^{\text {mapk }}$ antibody as described in Materials and Methods.

mic mice. NDGA did not interfere with major growth promoting signaling pathways such as the activation of receptor tyrosine kinases, PI3-kinase $/ \mathrm{p} 70^{\mathrm{s} 6 \mathrm{k}}$ or the ERK cascade demonstrating that NDGA is not acting as a general kinase inhibitor in pancreatic and cervical cancer cell lines. Many cancers have been shown to lose growth control as a result of defects in cell cycle control. Cyclin D1, which is crucial for promoting cell cycle progression, is constitutively expressed in pancreatic (Kornmann et al, 1998), but also in cervical cancer cells and could - at least in part be responsible for the transformed phenotype of these cells. Our data demonstrate that NDGA selectively inhibits constitutive cyclin D1 expression in both cancer cell lines providing a molecular mechanism of its growth inhibitory properties.

Inhibition of cyclin D1 can lead to cell cycle arrest and under certain circumstances to the induction of apoptosis (Tan et al,
2000). NDGA markedly induced apoptosis in SW 850 and C4-I cells in vitro and also in xenograft tumours established in athymic mice. This suggests that similar mechanisms mediate the effects of NDGA in vitro and in vivo. Again, the induction of apoptosis by NDGA was not due to inhibition of Ras-dependent survival pathways including the antiapoptotic kinase AKT. Instead, our data suggest that NDGA induces anoikis by disrupting the filamentous actin cytoskeleton in human pancreatic and cervical cancer cells. The effect of NDGA on actin stress fibers was comparable to that of cytochalasin D. In contrast to cytochalasin D, the effect of NDGA on the actin cytoskeleton appears to be cell type specific: NDGA could affect actin stress fibres in fibroblasts (Hirata et al, 1984; Chong et al, 1987), but failed to do so in leukocytes (Shalit et al, 1987) or keratinocytes (Coutant et al, 1997).

Anoikis is accompanied by induction of stress activated protein kinases (Frisch et al, 1996; Khwaja and Downward, 1997). Indeed, cytochalasin D potently induced activation of JNK1/2 in both cell lines. NDGA similarly activated JNK1/2 and $\mathrm{p} 38^{\text {mapk }}$ but had no effect on ERK1/2 activation in SW 850 and C4-I cells. Again, this effect of NDGA is likely to be cell type specific: No effect of NDGA on JNK activation could be demonstrated in vascular smooth muscle cells (Madamanchi et al, 1998), HeLa cells and HL 60 cells (Hii et al, 1998). There is some controversy regarding the possible role of stress activated protein kinases as mediators of apoptosis. For example, there is evidence that these kinases can mediate apoptosis under certain circumstances (Behrens et al, 1999; Tournier et al, 2000) including anoikis (Frisch et al, 1996). However, it has been questioned whether JNK activation occurring $30 \mathrm{~min}$ after suspending the cells by trypsinisation can contribute to anoikis (Khwaja and Downward, 1997). The sequence of events presented in this manuscript is different: We show that disruption of the actin cytoskeleton by NDGA is associated with activation of JNK and $\mathrm{p} 38^{\text {mapk }}$ and that both events precede cell detachment. The early activation of JNKs and $\mathrm{p} 38^{\text {mapk }}$ prior to cell detachment could contribute to anoikis. Our finding that similar concentrations of NDGA are required for disruption of actin stress fibres, JNK activation and the induction of apoptosis further supports our conclusion that these events could be related. However, the precise contribution of $\mathrm{JNK} 1 / 2$ and $\mathrm{p} 38^{\text {mapk }}$ activation to NDGA-induced cytoskeletal disruption and apoptosis requires further examination.

NDGA has been widely used as a specific lipoxygenase inhibitor. The precise relationship between the inhibitory effect of NDGA on lipoxygenases and the signalling events induced by NDGA described in this paper is not clear. Ding et al (1999a) described an inhibitory effect of NDGA on basal and 5-HETEinduced DNA synthesis in pancreatic cancer cells at concentrations comparable to those used in our experiments. This could suggest that some of the signalling events are related to the lipoxygenase inhibitory action of NDGA. However, the activation of JNKs and $\mathrm{p} 38^{\mathrm{mapk}}$ in response to NDGA seems to be cell type specific, whereas NDGA will inhibit lipoxygenases in virtually all cells. Thus, either the consequences of lipoxygenase inhibition are cell type specific or NDGA induces additional effects in a cell-type specific manner which are independent from its lipoxygenase inhibitory actions. Therefore, given the activation of multiple signalling events by NDGA, this compound should not be used anymore as a 'specific' lipoxygenase inhibitor without the examination of additional pathways.

The effect of NDGA on tumour growth observed in vivo was moderate but there was no toxicity detectable in the animals at the concentration used. The fact that NDGA seems to be effective against diverse and often incurable tumour types suggests that a more detailed analysis of the effects of NDGA on tumour growth in vivo is urgently required. Moreover, NDGA could provide a lead compound for the development of novel therapeutics in pancreatic and cervical cancer. 


\section{ACKNOWLEDGEMENTS}

T Seufferlein is supported by the Deutsche Forschungsgemeinschaft (SFB 518/B3); MJ Seckl is supported by Cancer Research UK. The authors thank F Genze for expert technical assistance.

\section{REFERENCES}

Anderson CNG, Tolkovsky AM (1999) A role for MAPK/ERK in sympathetic neuron survival: protection against a p53-dependent, JNK-independent induction of apoptosis by cytosine arabinoside. J Neurosci 19: 664-673

Avis I, Jett M, Boyle T, Vos M, Moody T, Tresto A, Martinez A, Mulshine J (1996) Growth control of lung cancer by interruption of 5-lipoxygenasemediated growth factor signaling. J Clin Invest 97: 806-813

Behrens A, Sibilia M, Wagner EF (1999) Amino-terminal phosphorylation of c-Jun regulates stress-induced apoptosis and cellular proliferation. Nature Genetics 21: $326-329$

Bonni A, Brunet A, West AE, Datta SR, Takasu MA, Greenberg ME (1999) Cell survival promoted by the Ras-MAPK signaling pathway by transcription-dependent and -independent mechanisms. Science 286: 1358 - 1362

Bossy-Wetzel E, Bakiri L, Yaniv M (1997) Induction of apoptosis by the transcription factor c-Jun. EMBO J 16: $1695-1709$

Brown EJ, Beal PA, Keith CT, Chen J, Shin TB, Schreiber SL (1995) Control of p70 s6 kinase by kinase activity of FRAP in vivo. Nature 377: 441-446

Carney DN, Gazdar AF, Minna JD (1980) Positive correlation between histological tumour involvement and generation of tumour cell colonies in agarose in specimens taken directly from patients with small cell carcinoma of the lung. Cancer Res 40: 1820-1823

Cavigelli M, Dolfi F, Claret FX, Karin M (1995) Induction of c-fos expression through JNK-mediated TCF/Elk-1 phosphorylation. EMBO J 14: $5957-$ 5964

Chang J, Skowronek MD, Cherney ML, Lewis AJ (1984) Differential effects of putative lipoxygenase inhibitors on arachidonic acid metabolism in cellfree and intact cell preparations. Inflammation 8: 143-155

Chen Y-R, Wang X, Templeton D, Davis R, Tan T-H (1996) The role of c-Jun $\mathrm{N}$-terminal kinase (JNK) in apoptosis induced by ultraviolet $\mathrm{C}$ and $\gamma$ radiation. J Biol Chem 271: 31929-31936

Chong AS, Parish CR, Coombe DR (1987) Evidence that the cytoskeleton plays a role in cell adhesion. Immunol Cell Biol 65: 85-95

Chou MM, Blenis J (1995) The 70 kDa S6 kinase: regulation of a kinase with multiple roles in mitogenic signalling. Curr Opin Cell Biol 7: 806-814

Coutant KD, Corvaia N, Ryder NS (1997) Bradykinin induces actin reorganization and enhances cell motility in HaCaT keratinocytes. Biochem Biophys Res Commun 237: 257-261

Datta SR, Brunet A, Greenberg ME (1999) Cellular survival: a play in three AKTs. Genes Dev 13: 2905-2927

Di Marzo V (1995) Arachidonic acid and eicosanoids as targets and effectors in second messenger interactions. Prostaglandins Leukot Essent Fatty Acids 53: $239-254$

Ding XZ, Iversen P, Cluck MW, Knezetic JA, Adrian TE (1999a) Lipoxygenase inhibitors abolish proliferation of human pancreatic cancer cells. Biochem Biophys Res Commun 261: 218-223

Ding XZ, Kuszynski CA, El-Metwally TH, Adrian TE (1999b) Lipoxygenase inhibition induced apoptosis, morphological changes, and carbonic anhydrase expression in human pancreatic cancer cells. Biochem Biophys Res Commun 266: $392-399$

Domin J, Higgins T, Rozengurt E (1993) Preferential inhibition of plateletderived growth factor-stimulated DNA synthesis and protein tyrosine phosphorylation by nordihydroguaiaretic acid. J Biol Chem 269: 8260 8267

Ferrari S, Thomas G (1994) S6 phosphorylation and the $\mathrm{p} 70^{\mathrm{s} 6 \mathrm{k}} / \mathrm{p} 85^{\mathrm{s} 6 \mathrm{k}}$. Crit Rev Bio Mol Biol 29: 385-413

Frisch SM, Francis H (1994) Disruption of epithelial cell-matrix interactions induces apoptosis. J Cell Biol 124: 619-626

Frisch SM, Vuori K, Kelaita D, Sicks S (1996) A role for Jun-N-terminal kinase in anoikis; suppression by bcl-2 and crmA. J Cell Biol 135: $1377-$ 1382

Ghosh J, Myers CE (1998) Inhibition of arachidonate 5-lipoxygenase triggers massive apoptosis in human prostate cancer cells. Proc Natl Acad Sci USA 95: $13182-13187$

Grewe M, Gansauge F, Schmid RM, Adler G, Seufferlein T (1999) Regulation of cell growth and cyclin D1 expression by the constitutively active FRAPp $70^{\mathrm{s} 6 \mathrm{~K}}$ pathway in human pancreatic cancer cells. Cancer Res 59: $3581-$ 3587
Haliday EM, Ramesha CS, Ringold G (1991) TNF induces c-fos via a novel pathway requiring conversion of arachidonic acid to a lipoxygenase metabolite. EMBO J 10: $109-115$

Han J, Lee JD, Bibbs L, Ulevitch RJ (1994) A MAP kinase targeted by endotoxin and hyperosmolarity in mammalian cells. Science 265: 808-811

Hii CS, Huang ZH, Bilney A, Costabile M, Murray AW, Rathjen DA, Der CJ, Ferrante A (1998) Stimulation of p38 phosphorylation and activity by arachidonic acid in HeLa cells, HL60 promyelocytic leukemic cells, and human neutrophils. Evidence for cell type-specific activation of mitogenactivated protein kinases. J Biol Chem 273: 19277-19282

Hirata M, Inamitsu T, Hashimoto T, Koga T (1984) An inhibitor of lipoxygenase, nordihydroguaiaretic acid, shortens actin filaments. J Biochem (Tokyo) 95: $891-894$

Khwaja A, Downward J (1997) Lack of correlation between activation of Jun$\mathrm{NH}_{2}$-terminal kinase and induction of apoptosis after detachment of epithelial cells. J Cell Biol 139: $1017-1023$

Korc M, Chandrasekar B, Yamanaka Y, Friess H, Büchler M, Beger HG (1992) Overexpression of the epidermal growth factor receptor in human pancreatic cancer is associated with concomitant increases in the levels of epidermal growth factor and transforming growth factor alpha. J Clin Invest 50: $1352-1360$

Kornmann M, Arber N, Korc M (1998) Inhibition of basal and mitogenstimulated pancreatic cancer cell growth by cyclin D1 antisense is associated with loss of tumourigenicity and potentiation of cytotoxicity to cisplatinum. J Clin Invest 101: $344-352$

Kurada P, White K (1998) Ras promotes cell survival in Drosophila by downregulating hid expression. Cell 95: 319-329

Kyriakis JM, Avruch J (1996) Protein kinase cascades activated by stress and inflammatory cytokines. BioEssays 18: $567-577$

Madamanchi NR, Bukoski RD, Runge MS, Rao GN (1998) Arachidonic acid activates Jun $\mathrm{N}$-terminal kinase in vascular smooth muscle cells. Oncogene 16: $417-422$

Muller C, Bockhorn AG, Klusmeier S, Kiehl M, Roeder C, Kalthoff H, Koch OM (1998) Lovastatin inhibits proliferation of pancreatic cancer cell lines with mutant as well as with wild-type K-ras oncogene but has different effects on protein phosphorylation and induction of apoptosis. Int J Oncol 12: $717-723$

Parrizas M, Saltiel AR, LeRoith D (1997) Insulin-like growth factor 1 inhibits apoptosis using the phosphatidylinositol 3 '-kinase and mitogen-activated protein kinase pathways. J Biol Chem 272: $154-161$

Peppelenbosch MP, Tertoolen LGJ, den Hertog J, de Laat SW (1992) Epidermal growth factor activates calcium channels by phospholipase A2/5lipoxygenase-mediated leukotriene C4 production. Cell 69: 295-303

Rondeau E, Guidet B, Lacave R, Bens M, Sraer J, Nagamine Y, Araillou R, Sraer JD (1990) Nordihydroguaiaretic acid inhibits urokinase synthesis by phorbol myristate acetate-stimulated LLC-PK1 cells. Biochim Biophys Acta 1055: $165-172$

Rozengurt E (1998) Signal transduction pathways in the mitogenic response to $G$ protein-coupled neuropeptide receptor agonists. J Cell Physiol 177: $507-517$

Sanchez-Perez I, Murguia JR, Perona R (1998) Cisplatin induces a persistent activation of JNK that is related to cell death. Oncogene 16: 533-540

Seufferlein T, Van Lint J, Liptay S, Adler G, Schmid RM (1999) Transforming growth factor alpha activates Ha-ras in human pancreatic cancer cells with Ki-ras mutations. Gastroenterology 116: 1441 - 1452

Shalit M, Dabiri GA, Southwick FS (1987) Platelet-activating factor both stimulates and 'primes' human polymorphonuclear leukocyte actin filament assembly. Blood 70: $1921-1927$

Sherr CJ (1993) Mammalian G1 cyclins. Cell 73: 1059- 1065

Tan A, Bitterman P, Sonenberg N, Peterson M, Polunovsky V (2000) Inhibition of Myc-dependent apoptosis by eukaryotic translation initiation factor 4E requires cyclin D1. Oncogene 19: 1437-1447

Taniguchi T, Kakkar AK, Tuddenham EG, Williamson RC, Lemoine NR (1998) Enhanced expression of urokinase receptor induced through the tissue factor-factor VIIa pathway in human pancreatic cancer. Cancer Res 58: $4461-4467$ 
Tournier C, Hess P, Yang DD, Xu J, Turner TK, Nimnual A, Bar-Sagi D, Jones SN, Flavell RA, Davis RJ (2000) Requirement of JNK for stressinduced activation of the cytochrome c-mediated death pathway. Science 288: $870-874$

Van Wauwe J, Goossens J (1983) Effects of antioxidants on cyclooxygenase and lipoxygenase activities in intact human platelets: comparison with indomethacin and ETYA. Prostaglandins 26: 725-730

Verheij M (1996) Requirement for ceramide-initiated SAPK/JNK signaling in stress-induced apoptosis. Nature 380: 75-79
Weinstein IB (1996) Relevance of cyclin D1 and other molecular markers to cancer chemoprevention. J Cell Biochem 25: 23-28

Xia Z, Dichens M, Raingeaud J, Davis RJ, Greenberg, ME (1995) Opposing effects of ERK and JNK-p38 MAP kinases on apoptosis. Science 270: $1326-1331$

Zanke BW, Boudreau K, Rubie E, Winnett E, Tibbles LA, Zon L, Kyriakis J, Liu F-F, Woodgett JR (1996) The stress activated protein kinase pathway mediates cell death following injury induced by cis-platinum, UV irradiation or heat. Curr Biol 6: 606-613 